\title{
Monitoring population decline: can transect surveys detect the impact of the Ebola virus on apes?
}

\author{
Céline Devos, Peter D. Walsh, Eric Arnhem and Marie-Claude Huynen
}

\begin{abstract}
In 2004 the Ebola virus caused a drastic decline in western gorilla Gorilla gorilla abundance at Lokoué Bai, a clearing in Odzala National Park, Republic of Congo. This decline was detected by observations of gorillas visiting the clearing. We confirm that the sympatric chimpanzee Pan troglodytes population was also affected by the Ebola outbreak, and test whether the decline in the ape population would have been detected with linetransect surveys, the most commonly used wildlife monitoring methodology in Central Africa. We also evaluate the potential of transect surveys for describing the extent and pinpointing the timing of drastic population declines when this information is not known from other evidence. Both nest survey using the marked nest count method and standing stock survey of other signs of ape presence (dung, feeding remains, prints) were able to detect the decline. However, only nests and dung were reliable indices for estimating the magnitude of the decline and accurately pinpointing the timing. It was necessary to pool data across many survey replicates because of small samples sizes. Our results suggest that transects methods are able to detect drastic changes in ape abundance but that large sample sizes are necessary to achieve adequate statistical power. We therefore recommend that those intending to use transect methods as tools for monitoring large forest mammals evaluate in advance how much effort will be necessary to detect meaningful changes in animal abundance.
\end{abstract}

Keywords Ebola virus, Gorilla gorilla, marked nest count, Pan troglodytes, population survey, Republic of Congo, standing stock survey.

\footnotetext{
Céline Devos* (Corresponding author) and Marie-Claude Huynen University of Liège, Department of Behavioural Ecology, 22 Quai Van Beneden, 4020 Liège, Belgium. E-mail celinedevos@swing.be

Peter D. WAlsh, Max Planck Institute for Evolutionary Anthropology, Department of Primatology, 6 Deutscher Platz, Leipzig 04103, Germany.

ERIC ARnhem ${ }^{\dagger}$ Free University of Brussels, Department of Anthropology \& Human Genetics, 1050 Brussels, Belgium

${ }^{*}$ Also at: Royal Belgian Institute of Natural Sciences, Biological Evaluation Section, 29 rue Vautier, 1000 Brussels, Belgium.

${ }^{\dagger}$ Also at: Projet Grands Singes - Centre for Research and Conservation, c/o Royal Zoological Society of Antwerp, B-2018 Antwerp, Belgium.

Received 23 January 2007. Revision requested 16 May 2007.

Accepted 1 August 2007.
}

\section{Introduction}

Wildlife monitoring is a critical tool for effective conservation because information on the distribution and abundance of large mammal populations is required for the formulation of conservation policy. A wide variety of methods are employed to survey mammal populations. Aerial surveys are commonly used in open or semi-open habitats but this method cannot be used to survey animals dwelling in dense forest because canopy cover limits aerial visibility (however, see Ancrenaz et al., 2004). Consequently, for many forest mammals ground surveys are required. However, direct sightings of such animals are rare in the forest understory and, because large samples are required to derive precise population estimates, surveys are usually based on indirect signs of presence. For example, dung piles are typically used to infer forest ungulate (Koster \& Hart, 1988) or forest elephant abundance (Barnes, 2001). An estimate based on dung counts requires estimates of dung pile density, defecation rate and dung decay rate. In the case of great apes, the most commonly used method for surveying population is based on counts of the sleeping nests apes make each night (Tutin \& Fernandez, 1984; Hall et al., 1998).

Most estimates of great ape distribution and abundance are based on standing stock survey methods, which use a single pass along line transects to count all visible ape nests. However, density estimates obtained from such surveys are controversial because of the numerous conversion factors (e.g. nest production and decay rates) needed to transform the number of nests encountered into number of animals. Because each conversion factor is an estimate with an associated error, the cumulative error from combining the conversion factors usually results in imprecise estimates of ape density (Plumptre, 2000; Kuehl et al., 2007). Furthermore, nest construction and decay rates have been estimated at a limited number of study sites, and extrapolation from one time or site to others also leads to large biases. For example, nest decay rate varies with the material used in nest construction (Tutin \& Fernandez, 1984) and climate (Walsh \& White, 2005). Consequently, the longevity of nests varies with season and each field sites' specific microclimate. To overcome these difficulties alternative sampling methods have been proposed such as the marked nest count method (Hashimoto, 1995; Plumptre \& Reynolds, 1996), which does not require a decay rate to calculate ape density. Transects are, rather, repeatedly surveyed to quantify the accumulation of new nests during 
discrete time intervals. Avoiding the calculation of decay rate reduces the number of conversion factors and should lead to more accurate density estimates. Although proposed $>10$ years ago this survey method has not been extensively tested. Here we examine how well ape monitoring systems based on marked nest counts can fulfil their intended function, detecting changes in ape abundance, using nest survey data that we collected around Lokoué Bai, a marshy clearing in north-west Republic of Congo that is very attractive to gorillas.

In addition to nests, various other signs of ape presence are visible on the forest floor, including dung, remains of feeding items (e.g. fruit parts, detached vegetation with basal part consumed) and hand and foot prints. Such signs are typically more numerous than ape nests and, in areas of low ape density, can be indicative of ape activity. To test whether they provide precise and unbiased inferences of ape density we therefore collected data on these other signs of ape presence during our surveys in Lokoué.

In the analyses reported here we exploit an unfortunate natural experiment: an Ebola outbreak in 2004 at Lokoué Bai. Direct observations at the clearing suggest that Ebola killed c. $95 \%$ of the 377 identified gorilla Gorilla gorilla that formerly frequented the clearing (Caillaud et al., 2006; see Gatti et al., 2004, for additional description of the visiting gorilla population). A sharp decline in gorilla visits to the clearing allowed Caillaud et al. (2006) to pinpoint when the outbreak started and ended. At the time of the outbreak, $\mathrm{CD}$ was monitoring the ape population (both gorilla and chimpanzee Pan troglodytes) in the forest surrounding the clearing. We have a time series of 14 repeat surveys with which to quantify ape density before and during the die-off.

Here we use our survey data on both nests and other signs to answer four questions about the sensitivity of surveys based on indirect signs in detecting changes in ape abundance: (1) Can transect data of indirect signs detect a decline when the date is known (from observations at the clearing)? (2) Can variation in sign encounter rate be used to quantify accurately the extent of the change? (3) Can indirect sign counts precisely pinpoint the timing of the die-off when the date is not predefined? (4) Which of the different types of sign typically recorded during large forest mammal surveys (i.e. nests, dung, feeding remains, and prints) can most accurately detect and describe this large and abrupt change in abundance?

\section{Methods}

\section{Study area}

The study site is in the north-east sector of the OdzalaKokoua National Park, Republic of Congo (Fig. 1a), c. 90 $\mathrm{km}$ north-east of the Lossi Sanctuary where Ebola outbreaks were reported to have killed 5,000 gorillas in 2002 and 2003 (Bermejo et al., 2006). The study site encompasses $42 \mathrm{~km}^{2}$ of lowland forest at altitudes of $300-600 \mathrm{~m}$ and is centered on Lokoué Bai, a 4 ha clearing that is frequently visited by gorillas (see Gatti et al., 2004, for further details of the site).

Before these Ebola outbreaks Odzala National Park was believed to harbour one of the largest great ape populations in Africa, with mean density estimates of 5.4 weaned gorillas and 2.2 weaned chimpanzees per $\mathrm{km}^{2}$ (Bermejo, 1999). However, Bermejo's surveys were conducted in the central part of the Park, all transects were located west of the Mambili River, and no specific abundance estimate was available for the east. Our study was initially designed to assess local population density in the eastern sector of the park and specifically around clearings, which are attractive resources to gorillas (see Devos et al., 2008, for details on ape densities).

\section{Study design and data collection}

We placed three concentric circular transects $\left(\mathrm{C}_{1}-\mathrm{C}_{3}\right)$ south of the Lokoué River at radial distances of 1,2 and $4 \mathrm{~km}$ from Lokoué clearing (Fig. 1b), and walked them once per month. All existing nests were recorded and marked during the first passage of the transects in November 2002. Following the marked-nest count method developed by Hashimoto (1995) and Plumptre \& Reynolds (1996), only newly detected nests were counted during subsequent surveys. Data recorded for each nest were: forest type, nest height, nest construction type (i.e. without vegetation, minimum amount of vegetation, herbaceous vegetation only, tree branches only, mixed vegetation), and identification of the plant species used to build the nest (adopted from Tutin et al., 1995). These characteristics were used in discriminant function analyses to discriminate between gorilla and chimpanzee nests. Nest sites were defined as clusters of nests of the same age class within $50 \mathrm{~m}$ of each other (Sanz et al., 2007).

We also recorded data on other signs of ape presence, including feeding remains, dung, hand and foot prints, direct sightings of apes and vocalizations at close range. When possible, prints and dung were assigned specifically to either chimpanzee or gorilla, with prints based on shape (gorilla prints being larger and shorter than chimpanzee prints) and dung based on both shape and texture (Tutin \& Fernandez, 1993). Feeding sites were not assigned to species because the same food items are consumed by both apes and processed in similar ways (Tutin \& Fernandez, 1992). All food remains of the same age, belonging to the same plant species, and found within a $20 \mathrm{~m}$ radius were considered a single feeding sign. For example, within a $20 \mathrm{~m}$ radius the observation of a single Marantaceae stem and the observation of a cluster of Marantaceae stems were both recorded as a single feeding sign if stems in the cluster 

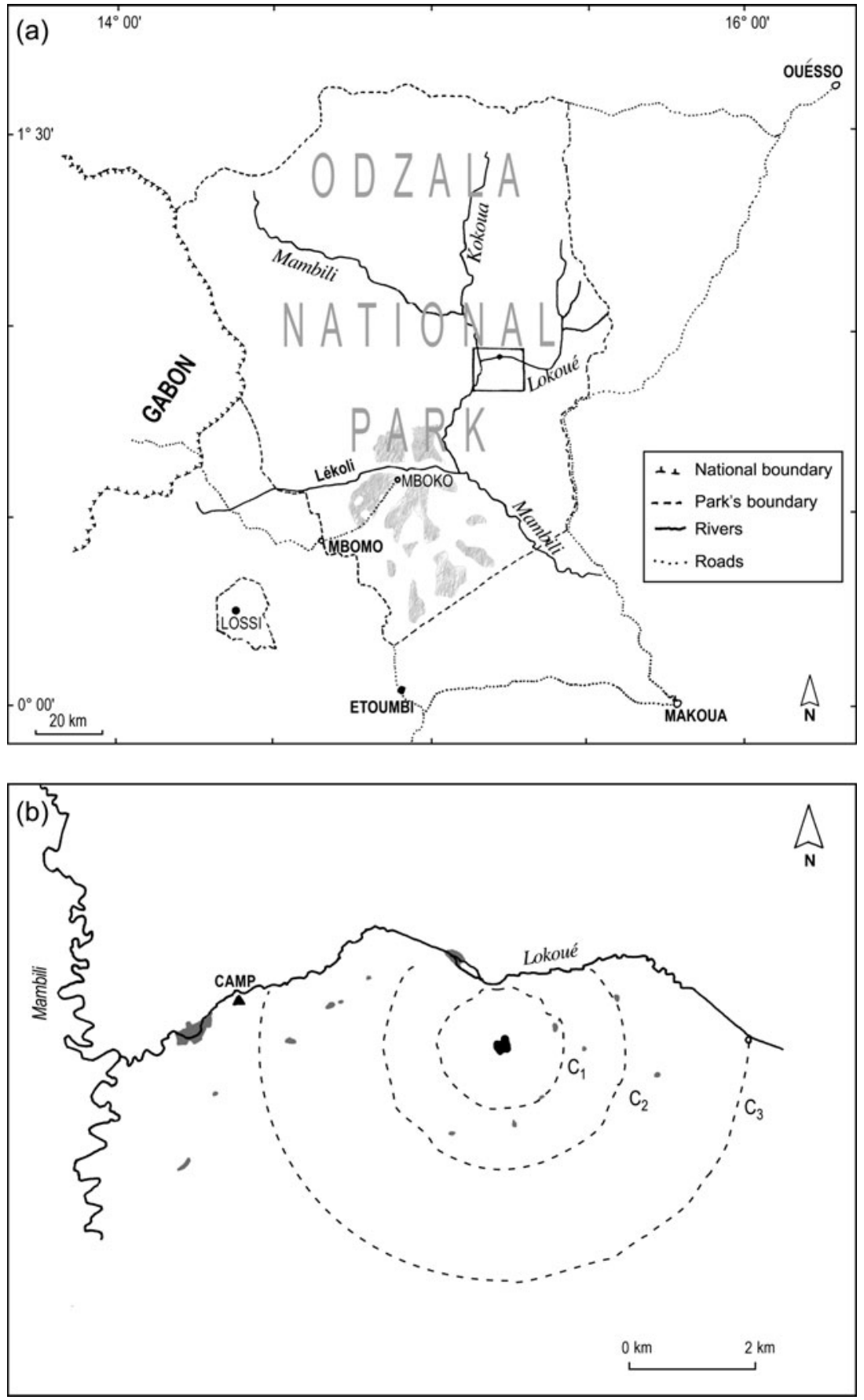

FIG. 1 (a) Location of Lokoué study area (rectangle on Lokoué River) within OdzalaKokoua National Park, Republic of Congo. (b) The three concentric survey transects (dashed lines), $\mathrm{C}_{1}-\mathrm{C}_{3}$, centered on Lokoué clearing (black-shaded area within $\mathrm{C}_{1}$ ). were all of the same age (thereby considered to constitute the remains of a single feeding session). The same recording technique was applied to prints and dung (as several prints or dung piles are often found at a distance when individuals walk or defecate while travelling).

\section{Data analysis}

We used discriminant function analysis to assign ape nests to either chimpanzee or gorilla. In this analysis discrimination is based on information associated with individual nests such as nest type, nest height, and site selection (see Sanz et al., 2007 for detailed description of discriminant function analysis, and Devos et al., 2008 for details on treatment applied to the Lokoué data set). Feeding remains, dung, prints, and direct contacts were pooled for both ape species and analysed as ape signs because of uncertainty in assigning some signs to species.

Caillaud et al. (2006) estimated that the Ebola outbreak at Lokoué began in December 2003 and lasted for almost 1 year, with most deaths occurring by May. On this basis we defined two distinct periods and analysis groups within the 
data collected over the different survey circuits: results of the nine circuits conducted before December 2003 were pooled together in one period (hereafter referred to as the 'before' period), and data from the five circuits conducted after December 2003 in another period (the 'after' period). $\chi^{2}$ tests were then used to determine if the encounter rates of ape signs differed between these two periods. This analytical approach assumes that (1) the number of signs encountered on transects is linearly proportional to ape abundance and, therefore, that (2) the number of ape sign recorded over the 14 walks were not spread homogeneously in time but biased toward the before period. Expected values (E) for the $\chi^{2}$ tests were calculated for each index type using:

$$
E=x \frac{n_{i}}{\left(n_{i}+n_{j}\right)}
$$

where $x$ is the total number of sightings recorded for the index during all surveys; $n_{\mathrm{i}}$ is the number of surveys walked during the before period, and $n_{\mathrm{j}}$ is the number of surveys walked during the after period.

Because data were collected during three distinct field seasons, ape nests accumulated between field seasons were marked during the first passage of each field season and excluded from trend analysis. For the other signs every survey month was included in the analysis as only fresh signs were recorded. Consequently, the number of surveys assigned to the before and after phases differed amongst signs (Table 1).

To examine whether repeated survey data can be used to pinpoint the actual timing of changes in abundance, we cut the time series into all possible two-period partitions. In other words, we started by comparing the first survey against the pooled data for all subsequent surveys. We then compared the first and second surveys against all others, and so on. For each pair of partitions we used the probability from a Student's $t$-test (two-sample, assuming equal variances) as a measure of the encounter rate difference. $\mathrm{P}$ is a good metric of the difference between partitions because its value depends not just on the means of the two partitions but also on the sample sizes. If we assume that most of the decrease in ape abundance occurred during a single short time interval, as suggested for gorillas by Caillaud et al. (2006), the time series partition revealing the lowest value of $\mathrm{P}$ would provide us with the best estimate of when the decrease occurred (i.e. where evidence of a change is maximal). Because the count data had a highly skewed distribution, we natural logarithmtransformed the data before conducting $t$-tests (adding 1 to all counts to avoid zero counts). Thus, these tests were sensitive to major, logarithmic (multiplicative) changes in count abundance rather than to smaller arithmetic fluctuations.

\section{Results}

Fourteen surveys were conducted over three field seasons between November 2002 and June 2004 (Season 1: November 2002-January 2003; Season 2: June 2003-November 2003; Season 3: February 2004-June 2004). As the Ebola outbreak at Lokoue is reported to have started in December 2003 (Caillaud et al., 2006), our last survey season covers a period in which ape density should have been substantially lower than in earlier seasons. Total length walked on each survey was $29.5 \mathrm{~km}\left(\mathrm{C}_{1}=6.4 \mathrm{~km} ; \mathrm{C}_{2}=9.6 \mathrm{~km}\right.$; $\mathrm{C}_{3}=13.5 \mathrm{~km}$ ), with all three circuits surveyed within an average of 7.7 days (range $=5-13$ days). A total of 1,224 indirect ape signs (6o nest sites, 1,012 feeding remains, 87 dung piles, 65 hand and foot prints) and 32 direct contacts were recorded. Discriminant function analysis assigned 21 nest sites to chimpanzees and 39 to gorillas.

Before the outbreak (Seasons 1 and 2), the mean number of nest sites recorded per survey (total along the three transects) was $7.86 \pm$ SE $4.41,5.14 \pm$ SE 3.80 , and $2.71 \pm$ SE 1.38 for apes, gorillas and chimpanzees, respectively (Fig. 2). These values fell to $1.25 \pm$ SE $0.5,0.75 \pm$ SE 0.95 , and $0.5 \pm$ SE 0.58 , respectively, during the epidemic (Season 3). This represents a decrease in ape nest sites encountered of $84.1 \%$ ( 85.4 and $81.6 \%$ for gorilla and chimpanzee nest sites, respectively). The decrease recorded in the other indices was $56.3 \%$ for feeding remains (which accounted for $80.5 \%$

TABLE 1 Details of the survey data used in statistical tests to detect differences in ape sign encounter rate before and after the documented Ebola outbreak.

\begin{tabular}{llllll}
\hline Index type & $\begin{array}{l}\text { Total no. of surveys } \\
\text { included in tests }\end{array}$ & $\begin{array}{l}\text { No. of surveys } \\
\text { before }\end{array}$ & $\begin{array}{l}\text { No. of surveys } \\
\text { after }\end{array}$ & Months & Note \\
\hline Nest sites & 11 & 7 & 4 & $12 / 2002-01 / 2003$ & $\begin{array}{l}\text { First month of each field } \\
\text { season not included }\end{array}$ \\
& & & & $07 / 2003-11 / 2003$ & \\
& & & $03 / 2004-06 / 2004$ & \\
$\begin{array}{c}\text { Dung, feeding remains, } \\
\text { prints \& direct contact }\end{array}$ & 13 & 8 & 5 & $11 / 2002-01 / 2003$ & Material failure precluded \\
& & & & $07 / 2003-10 / 2003$ data collection in Nov. 2003 \\
\hline
\end{tabular}



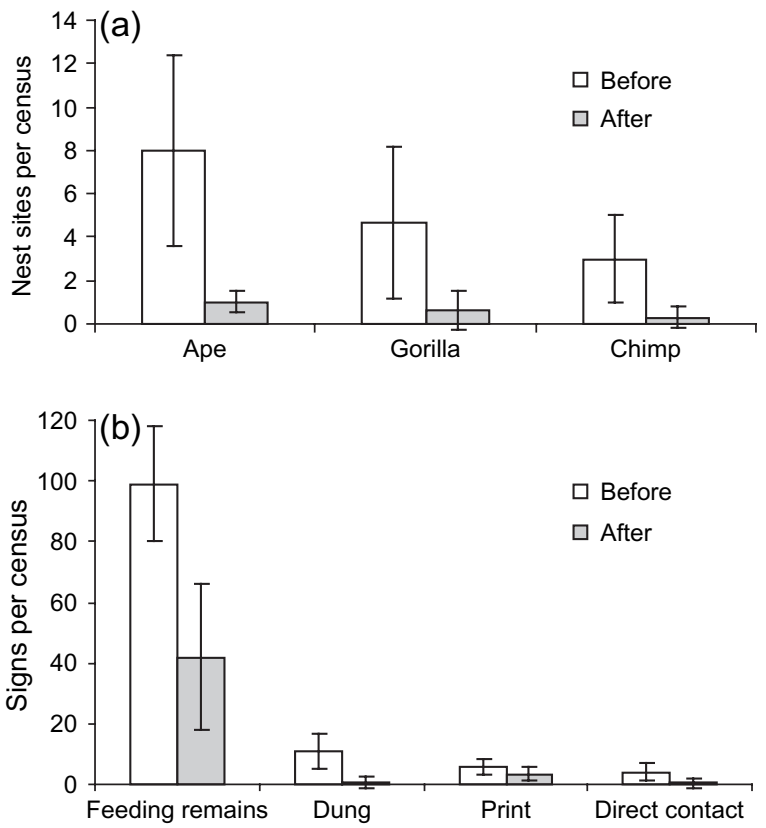

Fig. 2 Mean number of signs per census (with SE bars) observed along the survey trails before and after the estimated start of the Ebola outbreak in the Lokoué study area (Fig. 1). (a) Nest sites for both ape species, pooled and separately. (b) All feeding remains, dung, prints and direct contacts for both ape species pooled. $\chi^{2}$ tests $(\mathrm{df}=1, \mathrm{P}<0.01)$ indicated statistically significant differences between the before and after periods for all indexes except chimpanzee nest site and ape prints.

of all signs recorded), $90.2 \%$ for dung (6.9\% of all signs), $47.8 \%$ for prints $(5.2 \%$ of all signs), and $84.0 \%$ for direct contacts ( $2.5 \%$ of all signs). $\chi^{2}$ tests indicated a significant decrease in encounter rates between the before and after periods for all ape signs.

The raw distribution of nests recorded over the 11 walks (Fig. 3) has a large amount of stochasticity, making it difficult to pinpoint the precise date of decline. The results of $t$-tests comparing different partitions of the survey time series depended on the type of index tested. For ape and gorilla nest sites (Fig. 4a), the lowest $P$ value of successive tests appears when comparing the December 2002-November 2003 period to the March 2004-June 2004 period, thus correctly identifying the months between December
2003 and March 2004 as a time of major decline in abundance. For the chimpanzee nest site data, the lowest $\mathrm{P}$ value appeared one partition later (i.e. December 2002March 2004 vs April 2004-June 2004), implying a later start to the decline. Similarly, feeding remains suggested an onset of decline in the course of 2004 (Fig. 4b). Dung placed the onset at the end of 2003, the same as for the gorilla and ape nests data. Both prints and direct contacts (Fig. 4c), suggest a much earlier onset, with the lowest $\mathrm{P}$ value occurring for the partition November 2002-September 2003 vs October 2003-June 2004.

\section{Discussion}

Remaining great ape populations in the Congo Basin are seriously threatened by both poaching and recurrent outbreaks of the Ebola virus. It is, therefore, essential that monitoring programmes are well-planned and yield precise information that may aid in implementation of conservation strategies for the survival of great apes in this region. Our results show that data collected on transects via a widely used indirect survey method can be used to detect population changes. For all signs of ape abundance we examined, $\chi^{2}$ tests showed that sign encounter rates before the Ebola outbreak at Lokoué were significantly higher than those in the midst of the outbreak. However, the different signs examined differed in the size of the implied decline in ape numbers. Based on capture-recapture modelling of direct observations of gorilla visits to Lokoué clearing, Caillaud et al. (2006) estimated a 95\% decrease in gorilla abundance. The indirect signs that produced the closest estimate to this were nests and dung $(84-90 \%$ decrease in encounter rate). Feeding remains and prints produced much lower estimates of decline (c. 50\%). Direct observations and vocalizations recorded on forest survey trails gave an $84 \%$ estimate of decline.

The various signs also differed in the date they estimated for the epidemic's onset. Direct observations at the clearing suggested outbreak initiation in December 2003 (Caillaud et al., 2006), but only three of the seven indirect signs indicated the same date: gorilla nest sites, ape nest sites

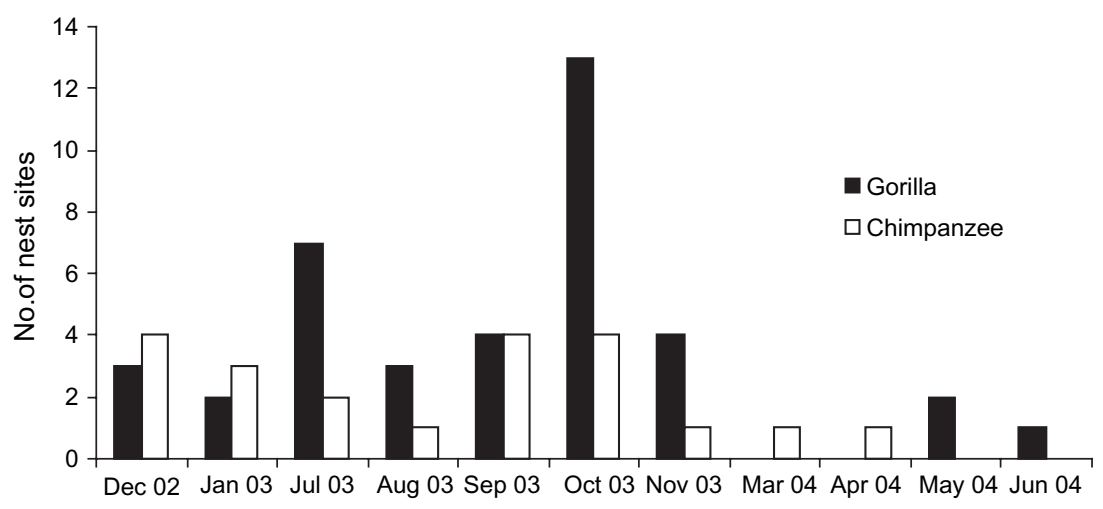

(c) 2008 Fauna \& Flora International, Oryx, 42(3), 367-374
FIG. 3 Number of gorilla and chimpanzee nest sites recorded per transect circuit in the Lokoué study area (Fig. 1) from December 2002 to June 2004. 

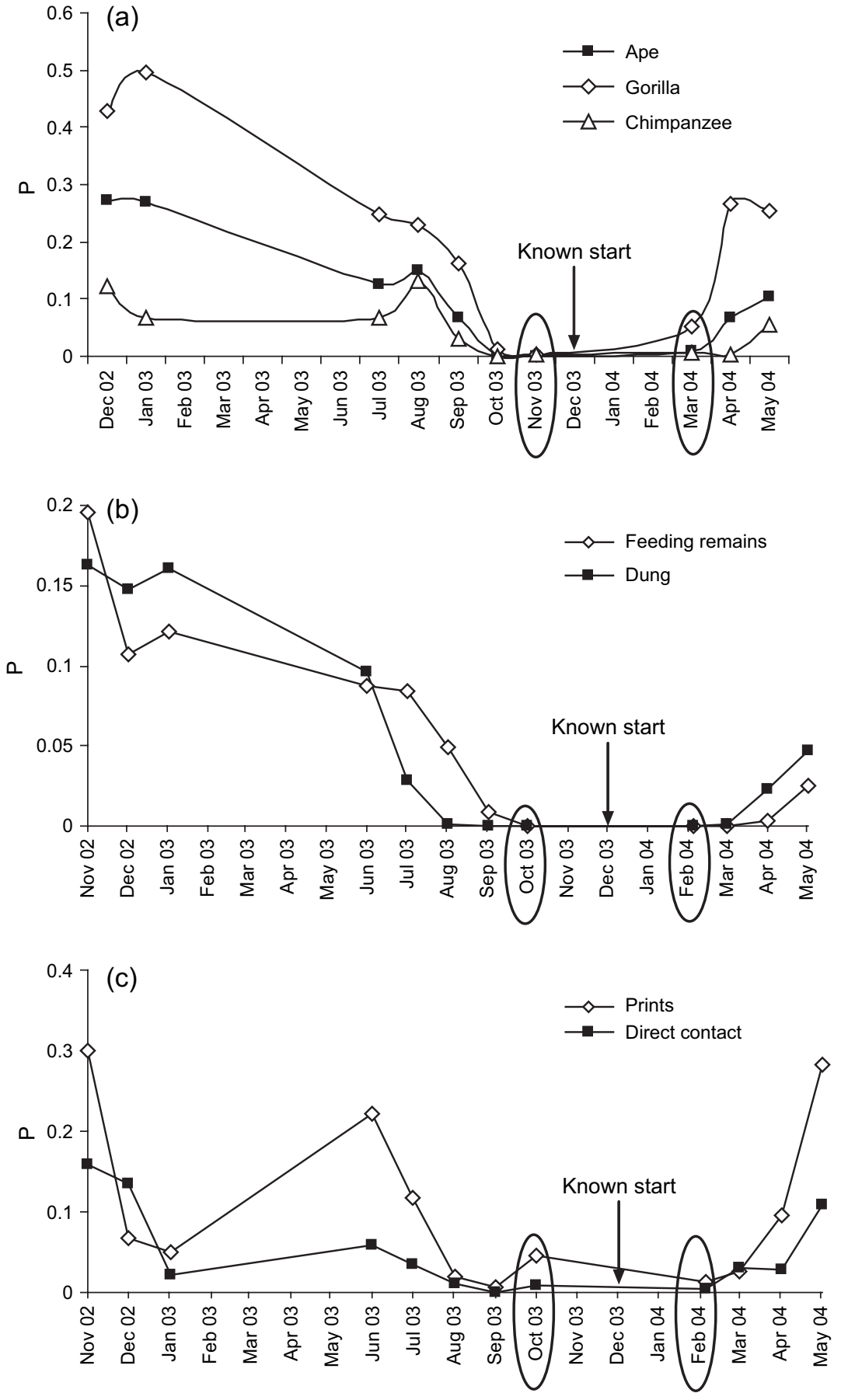

FIG. $4 \mathrm{P}$ values from Student's $t$-tests comparing the number of signs observed from December 2002 to May 2004 in successive time partitions. (a) Nest sites for both ape species pooled (ape) and separately (gorilla, chimpanzee). (b) Ape feeding remains and dung. (c) Ape prints and direct contacts. Ovals highlight the time partition with the lowest $\mathrm{P}$ value for each indirect ape sign. Arrows indicate the start of the Ebola virus outbreak, known from direct observation (Caillaud et al., 2006). (which is a pooling of both gorilla and chimpanzee nest sites) and ape dung. The other signs either over- or underestimated the date suggested by direct observations at the clearing. The issue of the timing of population change is critical because designing appropriate management responses requires relating a population decline to some threat factor. If monitoring programmes provide imprecise and/or biased information on the timing of a decline, it may be difficult to determine what caused it.

The differences amongst signs in the inferred sizes and dates of the decline underline two factors that are critical to consider when designing ape monitoring programmes: precision and bias. Some of the differences between signs were simply a matter of small sample size. For example, only 21 chimpanzee nest sites were recorded over 11 walks on the transects. Consequently, it took very little stochastic variation to shift the estimated size or date of the decline away from its true value. Direct visual or auditory contacts with apes were also too sparse $(\mathrm{n}=32)$ to produce precise and reliable estimates. Sample sizes for the other signs were higher but it was still necessary to pool circuits to detect significant changes in encounter rate or make precise 
estimates of the timing and size of the decline. The large between-circuit fluctuations in sign encounter rate also made it necessary to $\log$ transform the data to smooth the variance.

This emphasizes that conservationists need to be aware of the limits of their survey design and define what they want to be able to detect with their monitoring data. In our study each $30 \mathrm{~km}$ circuit was walked 14 times, with each circuit requiring $c .8$ days of work and three workers. Despite these 336 days of worker effort, our sample size was still inadequate to obtain clear answers to all of our questions. This has practical implications, as researchers planning marked-nest surveys will need to invest a large amount of survey effort, requiring large amounts of time and funding. Furthermore, our study was conducted in an area known for its high ape population density, and encounter rates of ape sign will often be much lower in other locations.

We analysed data reflecting a drastic and exceptional decline in abundance with a $95 \%$ mortality rate due to a deadly virus. Population decreases that monitoring systems wish to detect (e.g. related to poaching or habitat alteration) may typically be c. 30\% (Johns \& Skorupa, 1987; Plumptre \& Reynolds, 1996; and see Plumptre, 2000, for discussion on detection of density variation). In areas with low ape densities, monitoring programmes using similar methods and levels of effort may thus not be able to detect such changes in population abundance. Therefore, we urge those who hope to use indirect signs to detect subtle changes in ape abundance to evaluate explicitly the statistical power of their monitoring systems and budget efforts accordingly. Methods for using pilot study data to make such statistical power estimates are well-defined (Buckland et al., 2001).

The other issue raised by the observed inconsistency between signs of ape abundance is sampling bias. Using a given sign type as an index of abundance assumes there is a constant relationship between sign density and animal density (Walker et al., 2000) or, at least, that any heterogeneity in the relationship is quantified. This assumption was reasonably well upheld for nests and dung, as both produced estimates of decline date and size that were approximately equivalent to the values indicated by direct observation at the clearing. However, this assumption appeared to fail for the other sign types, with large errors in estimating the extent of the decline or its timing. These errors may have resulted from seasonal changes in the rate of sign decay, as may be expected through rainfall effects on the rate at which footprints wash away or feeding signs rot. Or they might have been due to seasonal differences in the rate at which signs were produced, as may happen if apes seasonally increased their consumption of food items that are highly visible or resistant to rot. Whatever the explanation, the consequence was that these signs proved to be unreliable indices of ape abundance. Thus, unless these seasonal variations in production or decay rate are quantified, we recommend against using prints and feeding remains as indices of ape abundance.

In summary, our results showed that data obtained from common monitoring approaches can be used to infer that a large die-off event has occurred. However, they also suggest that large sampling effort and sample size are needed to differentiate between stochastic variation in sign production/decay rates and real change in animal abundance. In addition, not all indices are appropriate for describing changes in population status. We have shown that to obtain a clear answer from the data, one must know the relationship between an index, such as ape sleeping nests, and the animal's actual abundance. Our results suggest that nest sites and dung may be the most reliable indicators of population change, and we recommend a focus on these signs in future surveys, with site- and time-specific sign production and decay rates estimated locally. However, as traditional decay rate estimation methods require extensive effort, there is still a need to design and test new methods for monitoring wildlife populations in tropical rain forests.

\section{Acknowledgements}

This research would not have been possible without the continued support of the Ministère de l'Economie Forestière et de l'Environnement of the Government of the Republic of Congo. Special thanks are due to the ECOFAC programme for support, logistics and permission to work in Odzala National Park. We particularly thank C. Aveling, J.M. Froment, L. Ndahiliwe and all members of the ECOFAC Composante Congo. All of the field staff at Lokoue deserve special recognition for their dedication. Surveys were funded by the Royal Institute for Natural Sciences of Brussels, the Fonds Léopold III pour l'Exploration et la Conservation de la Nature, the Fondation pour Favoriser les Recherches Scientifiques en Afrique, the Communauté française, and the Patrimoine de l'Université de Liège. CD would like to thank Christophe Boesch at the Max Planck Institute, Department of Primatology, for his warm welcome. We thank an anonymous reviewer for comments on the manuscript.

\section{References}

Ancrenaz, M., Gimenez, O., Ambu, L., Ancrenaz, K., Andau, P., Goossens, B. et al. (2004) Aerial surveys give new estimates for orangutans in Sabah, Malaysia. PLoS Biology, 3, e3.

BARNES, R.F.W. (2001) How reliable are dung counts for estimating elephant numbers? African Journal of Ecololgy, 39, 1-9.

Bermejo, M. (1999) Status and conservation of primates in Odzala National Park, Republic of Congo. Oryx, 33, 323-331.

Bermejo, M., Rodriguez-Teijeiro, J.D., Illera, G., Barroso, A., Vila, C. \& WALSh, P.D. (2006) Ebola outbreak killed 5,000 gorillas. Science, 314,1564 . 
Buckland, S.T., Anderson, D.R., Burnham, K.P., Laake, J.L., Borchers, D.L. \& Thomas, L. (2001) Introduction to Distance Sampling. Oxford University Press, London, UK.

Caillaud, D., Levrero, F., Cristescu, R., Gatti, S., Dewas, M., Dou A I, M. et al. (2006) Gorilla susceptibility to Ebola virus: the cost of sociality. Current Biology, 16, R489-R491.

Devos, C., Sanz, C., Morgan, D., Onononga, J., Laporte, N. \& Huynen, M. (2008) Comparing ape densities and habitats in northern Congo: surveys of sympatric gorillas and chimpanzees in the Odzala and Ndoki regions. American Journal of Primatology, $70,1-13$.

Gatti, S., Levrero, F., Menard, N. \& Gautier-Hion, A. (2004) Population and group structure of western lowland gorillas (Gorilla gorilla gorilla) at Lokoué, Republic of Congo. American Journal of Primatology, 63, 111-123.

Hall, J., White, L.J.T., Inogwabini, B.-I., Omari, I., Morland, H.S., Williamson, E.A. et al. (1998) A survey of Grauer's gorilla (Gorilla gorilla graueri) and chimpanzee (Pan troglodytes) in Kahuzi-Biega National Park and adjacent areas in Democratic Republic of Congo. International Journal of Primatology, 19, 207-235.

Hashimoto, C. (1995) Population census of the chimpanzees in the Kalinzu Forest, Uganda: comparison between methods with nest counts. Primates, 36, 477-488.

Johns, A.D. \& SkoRUPA, J.P. (1987) Responses of rain-forest primates to habitat disturbance: a review. International Journal of Primatology, 8, 157-191.

Koster, S.H. \& Hart, L.A. (1988) Methods of estimating ungulate populations in tropical forests. African Journal of Ecology, 26, 117-126.

Kuehl, H.S., Todd, A., Boesch, C. \& Walsh, P.D. (2007) Manipulating decay time for efficient large-mammal density estimation: gorillas and dung height. Ecological Applications, 17, 2403-2414

Plumptre, A.J. (2000) Monitoring mammal populations with line transect techniques in African forests. Journal of Applied Ecology, $37,356-368$.

Plumptre, A.J. \& Reynolds, V. (1996) Censusing chimpanzees in the Budongo Forest, Uganda. International Journal of Primatology, $17,85-99$.

Sanz, C., Morgan, D., Strindberg, S. \& Onononga, J.R. (2007) Distinguishing between the nests of sympatric chimpanzees and gorillas in the Goualougo Triangle, Republic of Congo. Journal of Applied Ecology, 44, 263-272.

Tutin, C.E.G. \& Fernandez, M. (1984) Nationwide census of gorilla and chimpanzee populations in Gabon. American Journal of Primatology, 6, 313-336.

Tutin, C.E.G. \& Fernandez, M. (1992) Comparison of food processing by sympatric apes in the Lope Reserve, Gabon. In Proceedings of the XIVth Congress of the International Primatological Society, Strasbourg (ed. R.H. Tuttle), pp. 280-281. IPS, Strasbourg, France.

Tutin, C.E.G. \& Fernandez, M. (1993) Faecal analysis as a method of describing diets of apes: examples from sympatric gorillas and chimpanzees at Lope, Gabon. Tropics, 2, 189-197.

Tutin, C.E.G., Parnell, R.J., White, L.J.T. \& Fernandez, M. (1995) Nest building by lowland gorillas in the Lope Reserve, Gabon: environmental influences and implications for censusing. International Journal of Primatology, 16, 53-76.

Walker, R.S., Pancotto, V., Schachter-Broide, J., Ackermann, G. \& Novaro, A.J. (2000) Evaluation of a fecal-pellet index of abundance for mountain vizcachas (Lagidium viscacia) in Patagonia. Mastozoologia Neotropical, 7, 89-94.

Walsh, P.D. \& White, L.J.T. (2005) Evaluating the steady state assumption: simulations of gorilla nest decay. Ecological Applications, 15, 1342-1350.

\section{Biographical sketches}

CÉLINE Devos's research interests are in ape population status assessment and socio-ecology, and she is currently researching gorilla feeding ecology, ranging and nesting behaviour in Odzala National Park. Peter Walsh specializes in the quantitative ecology of the large mammals of Central Africa, particularly apes and elephants. ERIC ARNHEM's research interests focus on human-wildlife conflict in unprotected areas. He is currently studying the impact of logging on mammal densities in Cameroon. Marie-Claude Huynen's research interests are in socio-ecology, habitat fragmentation and conservation of primate communities. She is currently supervising fieldwork in Guinea, Peru, Mexico and Thailand. 